\title{
Implementing the Indonesian Qualification Curriculum in Study Programs
}

\author{
Meini Sondang Sumbawati \\ The State University of Surabaya, East Java, INDONESIA \\ meini.sondang@yahoo.co.id
}

\begin{abstract}
The students is starting to feel restless on global competition with foreign workers to look for employment opportunities in many different fields of work and profession. How the Engineering Faculty of The State University of Surabaya (Unesa) effort to overcome the job competition in internal faculty. The Indonesian government has been set the Indonesian Qualifications Framework (IQF) which planned to implement in the year of 2015. IQF is the quality manifestation of national assessment system on the equality of learning outcomes which owned by Indonesia to increase a qualified and productive national employees resources. The purpose of this research is to discovery the chairman of department's perception about IQF. The methods use interview with an inclusive questionnaire. The results shows that the chairman has a regular updating in curriculum on each department as an effort to prepare of graduates who are qualified and productive.
\end{abstract}

Index Terms $-I Q F$, curriculum, qualified, productive.

\section{Introduction}

The curriculum serves as a tool to achieve the goal of education, it must be dynamic and flexible, be able to reach the future. In other words, the curriculum covers what should be studied by students to achieve learning outcomes, and give advantages for students in the future career.

The Curriculum in Indonesia is changed followed the science and technology development and the stakeholder needs. In 2013, it created the new curriculum that called 2013 curriculums as the replacement for the Curriculum Education Unit. Indonesia has imposed a CBC (Competency-Based Curriculum) as the curriculum for all levels of education, curriculum Education Unit. Although the curriculum changed by following the society development, but there still many problems.

In the other parts, Indonesia has a various kind of education such as academic, professional, and vocational. While the path consists of a formal education, non-formal, and informal. Higher education have the diploma, undergraduate, and graduate. The diversity of the impact are on the quality of graduates.

The problem that happened in Indonesia is the less harmony between the quality of a school or college graduates with an employee competency criteria that expected by stakeholders. Stakeholders not consider about the field and working experience, level of education, and job training that has obtained by the employee. In fact, there are differences in labor salary of a similar firm or industry to the graduate schools, colleges or private countries. The problem is Indonesia does not have a system of national equivalence assessment of learning outcomes.
The Ministry of Education and Culture, has been trying to harmonize between education and company through a cross-ministerial activities between the Ministry of Education and Culture and the Ministry of Manpower and Transmigration. The result of these activities, formulated the Indonesian Qualifications Framework (IQF). IQF substance developed in line with the quality of education and the national development and international labor which includes science, skills, and knowledge. All educational institutions should develop a new curriculum that refer to IQF, it has the standards quality that recognized by the stakeholders.

The State University of Surabaya (UNESA), as one of the State Universities in Indonesia, has been socialized IQF to all faculty leaders. Each faculty socialize to the head of departments to develop a new curriculum that is IQF oriented. How do the chairman in each department at the Tecnology Faculty (TF) of Unesa can understand about IQF? How to develop a new curriculum-IQF-oriented in theTF of Unesa?

\section{Literature Review}

\section{Curriculum}

The curriculum is the plans made for guide learning in schools, usually represented in retrievable documents of several levels of generality, and the implementation of those plans in the classroom; those experiences take place in a learning environment and also influences to what is learned" [Seel, 2004]. A curriculum as a document describing contents of subject matter domains, such as science, math, aims, and learning situations. Pinar [2005] stated, "curriculum is a set of skills in relation to goal setting, writing lesson objectives, lesson and unit planning, motivation of students, and selection of appropriate materials and aids".

In addition, Seel stated "curriculum consists of the knowledge and skills in subject matter areas that teachers teach and students are supposed to learn [1]. The curriculum generally consists of a scope or breadth of content in a given subject area and a sequence for learning"

Ralph Tyler quoted Pinar that the curriculum consists of (a) determine purposes, (b) identify learning experiences, (c) organize Reviews of these learning experiences, (d) Evaluate achievement in terms of stated purposes [2]. In attempts to give focus to curriculum centered people have tried to Reviews their thoughts on the teacher (as in the "teacher-centered curriculum"), on the child (as in the "child-centered curriculum"), on the structure of the disciplines (as in the "discipline-centered curriculum"), on society (as in the "society-centered curriculum"). 
The curriculum can be classified into (a) curriculum as a program planned and implemented in schools, and (b) curriculum as a program planned and implemented in a real classroom. Thus the curriculum serves as a tool to achieve educational goals, the curriculum should be able to "predict" events in the future. In other words, the curriculum covers what should be learned by student to achieve learning outcomes, and not what should be done by student.

McNeil reveals that there are five types of curriculum, namely: (a) the ideal curriculum, (b) the formal curriculum, (c) perceived curriculum, (d) operational curriculum, and (e) experiential curriculum [3]. The Ideal curriculum should be concerned with all parts and all our needs. Formal curriculum is the curriculum that constructed based on a curriculum that has been established in central or local government. This curriculum can be prepared based on the curriculum in similar education, and modification of the ideal curriculum, or a curriculum that has legality.

Curriculum development should refer to the government and the rapid development in the field of science and technology in particular vocational field. Therefore, it needs capabilities curriculum which organization-oriented and flexible, so the curriculum can adapt to any changes, both globally and locally. Related to the people needs in the area are varied, the curriculum content vocational and technology should also consider the industries in each region.

\section{Indonesian Qualifications Framework}

Indonesian Qualifications Framework (IQF) is the manifestation of quality learning outcomes assessment system of national equality. Work competence standards must be prepared by all stakeholders including government, private and public, including the industrial sectors and the business communities, education and training institutions, professional associations and so on, in order to be recognized by all parties. IQF as guidelines for:

a. qualifications set of learning outcomes acquired through formal education, non-formal, informal, training or work experience

b. qualifications recognition schemes define the learning outcomes acquired through formal education, nonformal, informal, training or work experience

c. qualification equalizes between learning outcomes that acquired through formal education, non-formal, informal, training or work experience

d. developed a method and recognition system of human resources qualifications from other countries who will work in Indonesia.

Need for packaging competency standards that have been standardized based on the jobs that exist in the workplace, in order to meet the needs of business and industrial field, by:

a. Needs "job qualification" which is expected by the field of small-scale businesses, medium and large.

b. Relevance of the hierarchy / jobs or skills appropriate to the field of business and industry as well as matching the description of IQF.

The main purpose of the assessment is the level of equality that all education programs in Indonesia, starting from high school level (high school, vocational school) to higher education (degree, diploma, specialist, post-graduate) are required to produce graduates with a minimum qualification that has equivalent qualification of IQF on the same level. In more detail, it has been prepared the description of derivation qualification of learning outcomes in graduate education programs every level of higher education for various fields of science or expertise.

IQF consists of 9 levels of learning outcome level which is agreed nationally. IQF consists of two parts (1) a general description and specific descriptions. General description describes the character, personality, work attitude, ethics, moral prevailing at every level. Specific description describe of coverage of science, knowledge, understanding (knowhow) and skills that a person relies on hierarchically controlled. Equalization learning outcomes generated through work experience with a level of qualification in the field and consider work experience, level of education, and job training that has been obtained. Learning outcomes expressed in the form of diplomas and certificates of competency.

\section{IQF Implementation in Curriculum}

In general, the curriculum consists of the knowledge and skills that taught by teacher. There is two aspects about how to develop new curriculum: (1) how can chairman of department understand about IQF? (2) how can chairman of department used to develop new curriculum-IQF-oriented for students at university?

The first, invite stakeholders such as vocational teachers and employers of the company or a related industry, to discuss the current conditions and expect future teachers and employers. In addition, employers discuss more detail about job profile in the industry, so it can be classified into core competencies, competencies and supporting competencies.

The second, develop learning outcomes with regard pedagogical competencies and professional competences. Then, grouping into competence component that consisting of: (1) basis of personality, (2) control science and skills, (3) work

abilty, (4) atitude and behavior in the work, and (5) social understanding. Learning outcomes in graduate level must be in accordance with the levels specified IQF that used as a reference for similar study programs in Indonesia. The formula is the minimal capabilities that should be owned by every graduate study program and put the (same position) as a core competence, graduate study program can be stated qualifications at level 6 of IQF. Description of level 6, students are expected to be able to (1) utilize science and technology in the field of expertise, and are able to adapt to the situation in problem solving, (2) control of certain areas of knowledge of theoretical concepts in general and specifically the theoretical concepts in the field of depth knowledge, and able to formulate procedural problem solving, (3) made a strategic decisions based on the analysis of information and data, and provide guidance in selecting the various alternative solutions, and (4) are responsible for their own work and be given responsibility for the achievement of the organization's work.

The parameter description consists of (1) the ability to work in the field, (2) the scope of work based on the essential knowledge, and (3) managerial capabilities. The elements of description ability in the field of work consists 
of: (1) able to do, (2) working manner, (3) the quality of the results, and (4) conditions. The elements of description consists of (1) the acquisition of knowledge, and (2) working ability. The elements of the managerial capabilities consist of managerial ability and attitude.

The third, prepare learning materials for undergraduate work refers to the vision and mission, as well as the competency program of study. Learning materials are prepared together with the branch field of study.

\section{Methods}

The research use survey method. The sample in this research is 4 chairman of department and 20 lecturers from the various background education, which are the Department of Electrical Engineering, Civil Engineering, Machine Engineering, and Home Economic. The time conducted on July to August, 2014 at TF of Unesa

To measure chairman of department's perception of IQF, an inclusive questionnaire was made based on two dimention. In one hand, items were extracted and adapted from previous curriculum and investigate how to develop the new curriculum. In another hand, the interview about perceptions of IQF through socialization experiences at university was conducted with a small samples of 4 chairman of department. During the interview, following questions were asked and discussed:

1. What do you know about the Indonesian Qualifications Framework (IQF)?

2. Do you find the easier communication among you, the tutors, and the faculty coordinators?

3. What do you know about the recently curriculum?

4. Does the socialization give information which makes you understand more about IQF?

5. Do you consider the learning materials useful in new curriculum-IQF-oriented?

6. Do you consider the tutorials help you to understand about learning outcomes?

7. Do you think that the new curriculum-IQF-oriented is an effective system to teach our students?

8. How can you develop the new curriculum?

9. What do you plan after the socialization about IQF?

10. Do you want invites the stakeholders from both vocational high schools and Industries to discuss about knowledge and skills experiences as required in employment?

\section{Result}

Most of the samples (90\%) agreed that in general they were understand about IQF. About $86 \%$ of the samples indicated that it was take much time to describe learning outcome, and nearly the same amount of them agreed that they found communication with tutors helpful for them. About $85 \%$ of the samples indicated that it was always beneficial to know the standard of the work expected. About half of the samples concurred that new curriculum-IQForiented was well designed (52\%), and the new curriculum required them to describe more detail $(47 \%)$.

The fact that most chairman of department showed optimistically on the new curriculum for helping their students to increase their interest to the courses. This type of curriculum can be particularly helpful for delivering courses which involve demonstrations and discussions, hands-on activities, and so on. Although results reveal that learning outcomes conflict and technical difficulty are still remaining, the continuation of develop new curriculum-IQForiented to support effective learning seems to be quite encouraging and promising.

One weakness in this study was the sampling. It should be noted that the sample was relatively small. Furthermore, the participants were selected by the convenient sampling method. Hence, the results of this study might not represent larger populations' perceptions on developing new curriculum-IQF-oriented. This weakness should be controlled in future studies.

The designer of curriculum can use different features and goals for this. The decision of which subjects and which content of a subject will be part of the written and executed curriculum depends on a complicated process of learning outcomes. In this process, the general needs of the students, societal needs, and industrial needs play their role in relation to the sector of education that is involved.

\section{Conclusions}

The results of this study indicated that chairman of department and lecturers perceived very positively on making the new curriculum. This result were approximately $86 \%$ of the chairman took part in develop new curriculum. Among of them, about $80 \%$ of the samples agreed that the new curriculum was helpful to their courses, and about $78 \%$ of the samples agreed that they could understand mostly what the tutor delivered in socialization. About $85 \%$ of the samples who attended the socialization section indicated that they were understand of learning outcomes. Overall, about $92 \%$ of the samples want invite stakeholders to discuss about knowledge and skills experiences as required in employment.

A curriculum is a plan to realize a goal of education. The content of a curriculum is the information and methods of a domain or of a different domains. Equalization learning outcomes generated through work experience with a level of qualification, work experience, level of education, and job training that has been obtained. Job competence standards must be prepared by all stakeholders including government, private and public, also including the industrial sectors and the business communities, education and training institutions, professional associations. IQF oriented in new curriculum should be finished and will execute on next year.

\section{Acknowledgment}

The author appreciates the support from all of chairman of departments and some lecturer in TF of Unesa who have participated on this study.

\section{References}

[1] McNeil, John D. (1990):Curriculum; A Comprehensive Introduction. Fourth Edition. Scott, Foresman/Little, Brown Higher Education, London.

[2] Pinar, William F. and Irwin, Rita L. (2005): Curriculum in a New Key; the Collected Works of Ted T. Aoki. Lawrence Erlbaum Associates, Inc., Mahwah, New Jersey London.

[3] Seel, Norbert M. and Dijkstra, Sanne. (2004). Curriculum, Plans, and Processes in Instructional Design. Lawrence Erlbaum Associates, Inc., Mahwah, New Jersey London. 